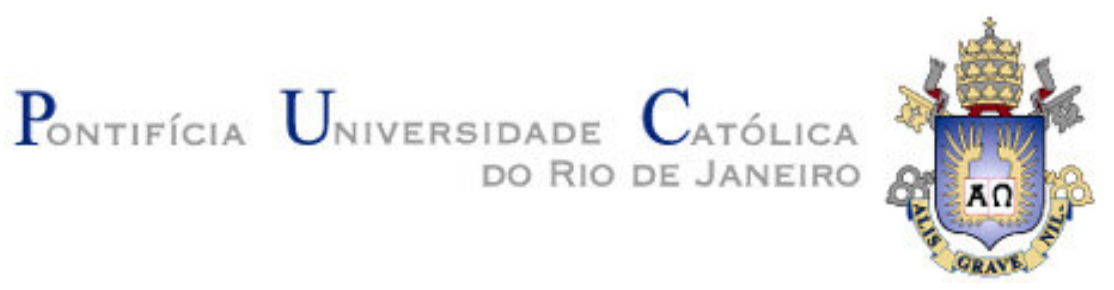

Carlos Frank Elias Calil

Posicionamento Social e Desempenho Financeiro: Uma Análise na Indústria Bancária Brasileira a partir de uma Tipologia Proposta

Dissertação de Mestrado

Dissertação apresentada como requisito parcial para obtenção do título de Mestre pelo Programa de PósGraduação em Administração da PUC-Rio.

Orientador: Jorge Ferreira da Silva

Rio de Janeiro, abril de 2006 


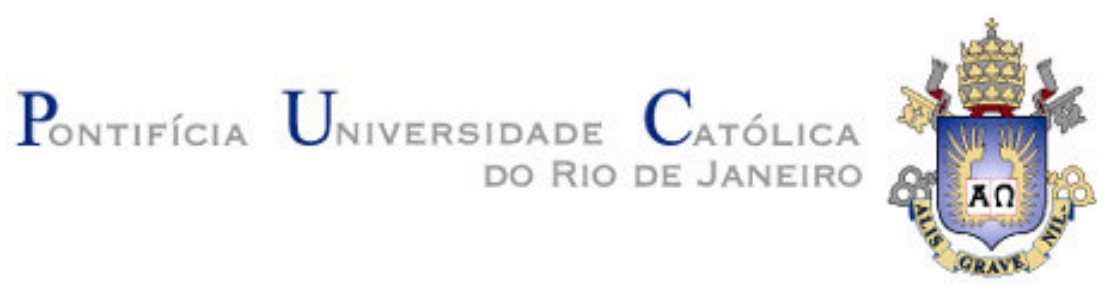

Carlos Frank Elias Calil

\section{Posicionamento Social e Desempenho Financeiro: Uma Análise na Indústria Bancária Brasileira a partir de uma Tipologia Proposta}

Dissertação apresentada como requisito parcial para obtenção do grau de Mestre pelo Programa de Pós-graduação em Administração de Empresas da PUC-Rio. Aprovada pela Comissão Examinadora abaixo assinada.

Prof. Jorge Ferreira da Silva Orientador Departamento de Administração - PUC-Rio

Prof. Marie Agnes Chauvel Departamento de Administração - PUC-Rio

Prof. Angela Maria Cavalcanti da Rocha Coppead - UFRJ

Prof. João Pontes Nogueira Vice-Decano de Pós-Graduação do CCS

Rio de Janeiro, 18 de abril de 2006 
Todos os direitos reservados. É proibida a reprodução total ou parcial do trabalho sem autorização da universidade, do autor e do orientador.

\section{Carlos Frank Elias Calil}

Graduado em Engenharia de Produção pela Universidade Federal do Rio de Janeiro com pós-graduação em Negócios Digitais Interativos para a Nova Economia na COPPE - UFRJ. Possuí experiência profissional na indústria financeira, de telecomunicações, varejo e de consultoria, exercendo cargos de gerência em empresas nacionais e multinacionais.

Ficha Catalográfica

Carlos Frank Elias Calil

Posicionamento Social e Desempenho Financeiro: Uma Análise na Indústria Bancária Brasileira a partir de uma Tipologia Proposta / Carlos Frank Elias Calil; Orientador: Jorge Ferreira da Silva. - Rio de Janeiro: PUC, Departamento de Administração, 2006.

100f. $30 \mathrm{~cm}$

Inclui referências bibliográficas.

1. Administração - Teses. 2. Estratégia. 3. Responsabilidade Social. 4. Desempenho. I. Silva, Jorge Ferreira da. II. Pontifícia Universidade Católica do Rio de Janeiro. Departamento de Administração. III. Título. 


\section{Agradecimentos}

Seria impossível agradecer a todas as pessoas que, direta ou indiretamente, contribuíram para esta dissertação.

Não poderia deixar de reconhecer o apoio material do CNPq para a realização deste trabalho e agradecer especialmente:

À minha esposa Jussara e à minha filha Amanda, a quem dedico este trabalho, que estiveram sempre pacientemente ao meu lado, motivando e servindo de inspiração.

Aos meus pais, Calil e Miriam, pelo esforço e dedicação para a minha formação.

Ao professor Jorge Ferreira da Silva, pela orientação sábia e pragmática.

Ao amigo Fábio de Oliveira Paula, pelo apoio e disponibilidade para os debates. 


\section{Resumo}

Carlos Frank Elias Calil. Posicionamento Social e Desempenho Financeiro: Uma Análise na Indústria Bancária Brasileira a partir de uma Tipologia Proposta. Rio de Janeiro, 2006. 100p. Dissertação de Mestrado - Departamento de Administração, Pontifícia Universidade Católica do Rio de Janeiro.

Este trabalho tem o propósito de buscar um maior entendimento quanto à possível existência de um impacto positivo no desempenho das empresas correlacionado com a adoção de uma estratégia focada em práticas socialmente responsáveis. Para tal, foi proposta e testada com um grupo de 21 empresas do setor bancário, uma tipologia para classificar de forma genérica 0 posicionamento das empresas, quanto ao modelo empregado de investimento social. Depois de classificadas as empresas à luz da tipologia proposta, foram analisadas por meio de estatística multivariada, a validação prática da tipologia, bem como a possível existência de diferença de desempenho, entre os diversos grupos enquadrados dentro das diferentes formas de posicionamento social, e o grupo sem posicionamento. Os resultados da pesquisa sugerem uma aceitação prática da tipologia proposta, através da formação de grupos estratégicos não vazios, para os clusters conceituais propostos. Também foi averiguado no estudo não haver diferença significativa de desempenho, tanto na comparação entre os grupos enquadrados pela tipologia, quanto entre estes e o grupo sem posicionamento, utilizando-se o ROA (retorno sobre ativos) e o ROE (retorno sobre o patrimônio líquido) como medidas de desempenho. Isso sugere que, para a amostra do setor bancário utilizada, o posicionamento social ainda não pode ser certificado como diferencial competitivo e fator determinante para 0 desempenho.

\section{Palavras-chave}

Estratégia; Responsabilidade Social; Desempenho 


\section{Abstract}

Carlos Frank Elias Calil. Social Positioning and Financial Performance: An Analysis of the Brazilian Banking Industry from a Proposed Typology. Rio de Janeiro, 2006. 100p. M.Sc. Dissertation. - Departamento de Administração, Pontifícia Universidade Católica do Rio de Janeiro.

This work aims to better understand the possible existence of a positive impact on the performance of companies correlated with the adoption of a strategy focused on socially responsible practices. For this, a typology was proposed and tested to generically rank a group of 21 companies in the banking sector as to the social investment model they had employed. After the companies had been classified within the typology proposed, the practical validation of the typology was analyzed by means of multivariate statistics. The possible existence of performance differences among the various groups within the different forms of social positioning, and also the group without any positioning, were also examined. The results of the research suggest a practical acceptance of the proposed typology, through the formation of non-empty strategic groups, for the proposed conceptual clusters. The lack of significant differences in performance was also investigated in the study, as much in the comparison between the groups within the typology, as in between these and the group without any positioning, with the utilization of the ROA (return on assets) and of the ROE (return on equity) as performance measurements. This suggests that for the banking sector sample utilized, the social positioning cannot yet be certified as a competitive advantage and as a determining factor for performance.

\section{Keywords}

Strategy; Social Responsibility; Performance 


\section{Sumário}

1 INTRODUÇÃO 10

1.1 Problema 10

$\begin{array}{lll}1.2 & \text { Objetivo } & 13\end{array}$

$\begin{array}{lll}1.3 & \text { Relevância do estudo } & 14\end{array}$

$\begin{array}{lll}1.4 & \text { Delimitação do estudo } & 15\end{array}$

1.5 Estrutura do Setor Bancário Brasileiro 16

2 REFERENCIAL TEÓRICO 23

2.1 Revisão da Literatura existente e Conceitos Centrais 23

$\begin{array}{lll}2.1 .1 & \text { Estratégia } & 23\end{array}$

2.1.1.1 Modelo SCP - Structure-Conduct-Performance 27

2.1.1.2 Tipologias Estratégicas 32

2.1.1.3 RBV - The Resource-Based View 35

$\begin{array}{lll}2.1 .2 & \text { Desempenho } & 38\end{array}$

2.1.3 Responsabilidade Social Empresarial 44

2.1.3.1 Corporate Social Responsiveness $\quad 51$

2.1.3.2 Responsabilidade Social e Desempenho 51

2.1.4 Desempenho Social 53

2.1.4.1 Balanço Social 56

2.1.5 Marketing Social Empresarial $\quad 60$

2.2 Tipologia para avaliar-se o posicionamento do Investimento Social

Externo 64

2.3 Identificação do Constructo 68

$\begin{array}{lll}2.4 & \text { Hipóteses a serem testadas } & 69\end{array}$

3 METODOLOGIA $\quad 71$

$\begin{array}{lll}3.1 & \text { Tipo de pesquisa } & 71\end{array}$

3.2 Universo, Amostra e Coleta de Dados 72

$\begin{array}{lll}3.3 & \text { Tratamento dos dados } & 78\end{array}$

$\begin{array}{llr}3.4 & \text { Resultados } & 86\end{array}$

3.5 Limitações do método 90

3.6 Conclusões 92

4 LISTA BIBLIOGRÁFICA 96 


\section{Lista de figuras}

FIGURA 1 - A Roda da Estratégia Competitiva 25

FIGURA 2 - Contexto onde a Estratégia Competitiva é Formulada 26

FIGURA 3 - Modelo das Cinco Forças - Porter (Forças que dirigem a Concorrência na Indústria) $\quad 29$

FIGURA 4 - Forças que Influenciam a Atratividade da Arena Competitiva 31

FIGURA 5 - Domínios do Desempenho do Negócio 42

FIGURA 6 - Empresa e Stakeholders 48

FIGURA 7 - Pirâmide da Responsabilidade Social Empresarial 50

FIGURA 8 - Modelo de Balanço Social - IBASE 58

FIGURA 9 - Elementos do Marketing Mix e Forças Externas 62

FIGURA 10 - Quatro Estratégias Sociais Genéricas $\quad 67$

FIGURA 11 - Representação dos Construtos $\quad 69$

FIGURA 12 - Bancos que compuseram a amostra final 73 


\section{Lista de tabelas}

$\begin{array}{ll}\text { TABELA } 1 \text { - Bancos por origem de capital } & 17\end{array}$

TABELA 2 - Rede de Atendimento 18

TABELA 3 - Atendimento Bancário por Origem de Capital (base Dez/2004) 18

TABELA 4 - Número de Contas e Internet Banking (base Dez/2004) 19

TABELA 5 - Administração de recursos de terceiros (base Dez/2004) 19

TABELA 6 - Transações com Cartões de Crédito (base Dez/2004) 20

TABELA 7 - Maiores Bancos do País por Depósito Total (base Jun/2005) 21

TABELA 8 - Abordagem VRIO 37

TABELA 9 - Efeitos da Empresa e da Indústria sobre o Desempenho (variável dependente - ROA) 43

TABELA 10 - Política Social da Empresa: Amostra de Resultados da Ação Orientada aos Princípios da Responsabilidade Social Empresarial $\quad 55$

TABELA 11 - Dados Coletados - Variáveis Independentes 75

TABELA 12 - Dados Coletados - Variáveis Dependentes 77

TABELA 13 - Base Normalizada - Transformada Z 79

TABELA 14 - Teste de Normalidade $\quad 80$

TABELA 15: Simplificação do Espaço Estratégico 81

TABELA 16 - Simplificação do Espaço Estratégico II - \% da Variância Explicada $\quad 82$

TABELA 17 - Correlação entre as Variáveis $\quad 82$

TABELA 18 - Resumo do Tratamento dos Dados 84

TABELA 19 - Matriz alvo dos Centróides Teóricos 87

TABELA 20 - Distribuição de empresas por grupo estratégico 87

TABELA 21 - Matriz alvo dos Centróides Obtidos 88

TABELA 22 - Teste dos Sinais dos Postos de Wilcoxon 88

TABELA 23 - Teste Lâmbda de Wilks 89

TABELA 24 - Média de Desempenho obtida por cada um dos grupos - ROA e ROE $\quad 89$

TABELA 25 - Diferença de Desempenho entre Grupos - ROA e ROE 90 